\title{
The discovery of herbal drugs and natural compounds as inhibitors of SARS-CoV-2 infection in vitro
}

\author{
Mya Myat Ngwe Tun ${ }^{1}\left[\right.$ ' Kazufumi Toume ${ }^{2} \cdot$ Elizabeth Luvai $^{1} \cdot$ Khine Mya Nwe $^{1} \cdot$ Shusaku Mizukami ${ }^{3}$. \\ Kenji Hirayama ${ }^{3} \cdot$ Katsuko Komatsu $^{2} \cdot$ Kouichi Morita $^{1}$
}

Received: 13 August 2021 / Accepted: 14 December 2021 / Published online: 10 January 2022

(c) The Japanese Society of Pharmacognosy 2022

\begin{abstract}
The emergence of the severe acute respiratory syndrome coronavirus 2 (SARS-CoV-2) pandemic in 2019 has led to a global health crisis. Mutations of the SARS-CoV-2 genome have impeded the development of effective therapeutics and vaccines against SARS-CoV-2. Natural products are important for discovering therapeutics to treat the 2019 coronavirus disease (COVID-19). In the present study, we investigated the antiviral activity of herbal drug extracts from Polygala Root, Areca, and Quercus Bark and natural compounds derived from herbal drug such as baicalin and glabridin, with $\mathrm{IC}_{50}$ values of $9.5 \mu \mathrm{g} / \mathrm{ml}, 1.2 \mu \mathrm{g} / \mathrm{ml}, 5.4 \mu \mathrm{g} / \mathrm{ml}, 8.8 \mu \mathrm{M}$, and $2.5 \mu \mathrm{M}$, respectively, against SARS CoV-2 infection in vitro. Certain herbal drug extracts and natural compounds were found to inhibit viral RNA levels and infectious titers of SARS-CoV-2 in a dosedependent manner. Furthermore, viral protein analyses showed that herbal drug extracts and natural compounds effectively inhibited SARS-CoV-2 in the various entry treatments. Our study revealed that three herbal drugs are good candidates for further in vivo and clinical studies.
\end{abstract}

Keywords SARS-CoV-2 $\cdot$ Polygala root $\cdot$ Areca $\cdot$ Quercus bark $\cdot$ Baicalin $\cdot$ Glabridin

\section{Introduction}

The outbreak of the coronavirus disease in 2019 (COVID19) caused by severe acute respiratory syndrome coronavirus 2 (SARS-CoV-2) has caused a serious threat to public health globally [1]. A novel beta coronavirus, SARS-CoV-2 (family Coronaviridae, order Nidovirales), is an enveloped, positivesense, single-stranded RNA virus that causes an acute respiratory disease with an approximate $10.2 \%$ mortality rate

Mya Myat Ngwe Tun

myamyat@tm.nagasaki-u.ac.jp

Kouichi Morita

moritak@nagasaki-u.ac.jp

1 Department of Virology, Institute of Tropical Medicine, Nagasaki University, 1-12-4 Sakamoto, Nagasaki City 852-8523, Japan

2 Section of Pharmacognosy, Institute of Natural Medicine, University of Toyama, 2630 Sugitani, Toyama 930-0194, Japan

3 Department of Immune Regulation, Shionogi Global Infectious Diseases Division, Institute of Tropical Medicine, Nagasaki University, Nagasaki 852-8523, Japan
$[2,3]$. The World Health Organization (WHO) declared the rapidly spreading disease a pandemic on 11 March 2020 [4]. As of 10 December 2021, over 267 million confirmed cases and more than 5 million deaths had been recorded in more than 210 countries [5]. COVID-19 is characterized by high infectivity and marked variability in clinical severity from asymptomatic to mild, severe, or critical [6]. SARS-CoV-2 mainly enters human cells by binding to the receptor of an angiotensin-converting enzyme 2 (ACE2) [7]. The ACE2 receptor is expressed on cells throughout the body in the lungs, nose, blood vessels, heart, intestine, and parts of the brain [8]. The virus genomic RNA is released into the cytoplasm and creates a new RNA virus, using the host cell to assemble new virus particles. The new copies of the virus spread into the environment and infect other cells and organs in the body [9]. Eight vaccines (Pfizer-BioNTech, Moderna, Janssen, AstraZeneca-Oxford, Sinovac Biotech, Gamaleya, CanSino Biologics, and Sinopharm) are now available to the public; however, they are only available in limited quantities in at least 122 countries [10]. Although vaccination has commenced worldwide, it will take a long time to safely attain herd immunity against COVID-19 through vaccination; therefore, effective therapies are still required 
to prevent and treat COVID-19 [11]. Clinical investigations have focused on several approved antiviral drugs, including remdesivir [12] and favipiravir [13]. Additionally, several traditional herbal medicines have been reported as having inhibitory effects on SARS-CoV-2 infection in vitro and in vivo $[14,15]$. Despite numerous clinical trials for the treatment of COVID-19, there is still a need to expand the number of possible drug candidates and drug combinations that could have antiviral effects for the treatment of COVID19. To identify anti-SARS-CoV-2 drugs we screened 120 herbal extracts, 96 Kampo-related active compounds from a Kampo library which provided by the Institute of Natural Medicine (WAKANKEN) at the University of Toyama [16]. After selected through the first in vitro assay, we detected three positive herbal extracts and two natural compounds for possible antiviral effect on SARS-CoV-2 infection. This study evaluated the inhibitory effects of those herbal drug extracts and natural compounds against SARS-CoV-2 infection in vitro.

\section{Experimental}

\section{Virus and cells}

The SARS-CoV-2 (TY/WK-521, Japan, 2020) was provided by the National Institute of Infectious Disease, Japan, and was propagated in Vero E6 cells cultured in MEM supplemented with $10 \%$ fetal calf serum. Virus stocks were kept in $\mathrm{a}-80{ }^{\circ} \mathrm{C}$ freezer as aliquots until testing. All experiments using infectious SARS-CoV-2 were performed in a Biosafety Level 3 laboratory at Nagasaki University according to standard BSL3 guidelines.

\section{Herbal drugs and natural compounds}

All herbal drugs used in this study were purchased from Tochimoto Tenkaido (Osaka, Japan). The Polygala Root extract (ext.), Areca ext., and Quercus Bark ext. were prepared from Polygala Root (TMPW28828), Areca (TMPW28896), and Quercus Bark (TMPW28902), respectively, using following procedure. Each herbal drug $(30.0 \mathrm{~g})$ was boiled gently with $300 \mathrm{~mL}$ of purified water for $60 \mathrm{~min}$. Then, the supernatant of the decoction was lyophilized to obtain dry extract. The extracts were dissolved in purified water at a concentration of $10 \mathrm{mg} / \mathrm{mL}$ and kept at $-20{ }^{\circ} \mathrm{C}$ prior to use. The voucher specimen of these herbal drug extracts were deposited in the Museum of Materia Medica, Institute of Traditional Medicine (TMPW), University of Toyama, Japan. The natural compounds baicalin and glabridin were purchased from FUJIFILM Wako pure chemical corporation (Osaka, Japan). The structure of baicalin and glabridin were described (see the Electric Supplementary Material).

\section{Viral RNA extraction and quantitative real-time RT-PCR}

The $100 \mu$ of infected cell supernatant were harvested for viral RNA extraction by the Nextractor NX-48 robot, using the NX-48S Viral NA Kit (Genolution Inc.), according to the manufacturer's instructions. A volume of $5 \mu \mathrm{l}$ of RNA was used for quantitative real-time RT-PCR (qRT-PCR), and amplification of the nucleocapsid (NP) gene was performed using a total of $20 \mu \mathrm{l}$ of reaction mixture consisting of $5 \mu \mathrm{l}$ of Taqman master mix, $7 \mu \mathrm{l}$ of nuclease water, $1 \mu \mathrm{l}$ of $0.5 \mu \mathrm{M}$ forward and reverse primers, and $1 \mu \mathrm{l}$ of $0.25 \mu \mathrm{M}$ probe with SARS-CoV-2 N primers of TaqMan Fast Virus 1-Step Master Mix (Life Technologies, CA, USA) [17]. The primers and probes were referred to in the previous report [18].

\section{Virus titration by focus assay}

Virus titer was determined by a focus-forming assay in 96-well plates of Vero E6 cells, as described previously, with some modifications [19]. Infected cell supernatants were diluted in a tenfold serial dilution and added to 96-well plates in duplicate. After $1.5 \mathrm{~h}(\mathrm{~h}), 2 \%$ FCS methylcellulose was added and incubated at $37{ }^{\circ} \mathrm{C}$ and $5 \% \mathrm{CO} 2$. Immunostaining was performed using anti-SARS-CoV-2 NP protein mouse monoclonal antibody (ADTEC, Oita, Japan) as the primary antibody, followed by HRP-conjugated goat anti-mouse IgG-106 PU (American Qualex, CA, USA) as the secondary antibody. The bound conjugate was visualized by adding substrate $3,3^{\prime}$ diaminobenzidine tetrahydrochloride (Wako, Tokyo, Japan) containing hydrogen peroxide. Foci were counted and expressed as focus-forming units (FFU/ml).

\section{Cell viability assay}

Vero E6 cells in 96-well plates were treated with samples for 3 days. The cell viability assay was also conducted in parallel with the antiviral assay. To determine the concentration that causes a 50\% reduction in cell survival (CC50), cell viability assay was evaluated by MTT [3-(4,5-dimethylthiazol-2-yl)-2, 5-diphenyl tetrazolium bromide] according to the manufacturer's instructions (Promega, WI, USA). Optical density was measured at $570 \mathrm{~nm}$, read using a microplate reader (Synergy H1 M, Biotech). Cells with culture medium were used as negative control (cell control). Cell viability was determined using the following equation: cell viability $(\%)=($ sample value $) /($ cell control $) \times 100$. Additionally, viral inhibition (IC50) was calculated as viral inhibition 
$(\%)=$ quantity of virus copies in (virus control - sample)/ virus control $\times 100$.

\section{Immunofluorescence microscopy}

For the immunofluorescence (IFA) assay by microscopy experiment, Vero E6 cells in 8 well glass slides (Millipore, Massachusetts, USA) were infected with SARS-CoV-2 at multiplicity of infection (MOI) of 0.02 , then herbal drug extracts or compounds were added and left for 2 days. The cells were fixed with $4 \%$ paraformaldehyde overnight. The cells were permeabilized by $1 \%$ NP-40 and blocked using Blockace (Yukijirushi, Sapporo, Japan) at room temperature. The cells were stained with anti-mouse SARS-CoV2-NP protein (Gene Tex, CA, USA) as the primary antibody and Alexa Fluor 488 goat anti-mouse IgG (Invitrogen, MA, USA) as the secondary antibody. The nuclei were determined with Hoechst 33,342 dye (Southern Biotech, AL, USA). The cells were imaged by Keyence (BZ-X710) microscopy (Keyence, IL, USA) using a $10 \times$ lens.

\section{Western blot analysis}

Protein expression was examined by western blot analysis. Vero E6 cells were infected with SARS-CoV-2 (MOI 0.1) and harvested at $16 \mathrm{~h}$ post-infection (pi) and then lysed using a RIPA buffer. The equal volume of cell lysate and sample buffer $(2 \times$ concentrated SDS that included $25 \mathrm{M}$ Tris-HCL (pH 6.8), 4\% SDS, 2\% 2-mercaptoethanol, 20\% glycerol, and $0.01 \%$ bromophenol blue) was mixed and incubated at $100{ }^{\circ} \mathrm{C}$ for $10 \mathrm{~min}$. The sample protein was separated on 5-20\% SDS-PAGE and blotted on a PVDF membrane. After blocking with 5\% skim milk, the membrane was stained with a 1:500 dilution of anti-rabbit SARS-CoV-2 N protein (Gene Tex, CA, USA) as the primary antibody and horseradish peroxidase-conjugated anti-rabbit IgG (102 PU, American Qualex, CA, USA) as the secondary antibody. The protein bands were detected by immersing the membrane into a 3,3'-diaminobenzidine tetrahydrochloride solution.

\section{Statistical analysis}

Data were analyzed using SPSS for Windows, version 16.0 (IBM Corp., Armonk, NY). GraphPad Prism 9 (GraphPad Software, Inc., San Diego., CA, USA) was used. Continuous variables were presented as mean value \pm SD. Group comparisons were performed using one-way analysis of variance (ANOVA). A Student's $t$ test was used to compare continuous variables between two groups. For all calculations, a $p$ value of less than 0.05 was considered statically significant.

\section{Results}

An antiviral activity assay was performed to evaluate the antiviral effect of three herbal drug extracts from Polygala Root, Areca, Quercus Bark, and two natural compounds, baicalin and glabridin, against SARS-CoV-2 infection. The herbal drug extracts and compounds were diluted in $2 \%$ FCS minimum essential medium (MEM) with different concentrations. One day before infection, Vero E6 cells were seeded in 96-well plates. The cells were treated with the tested substances in the form of diluted herbal drug extracts or compounds for $1 \mathrm{~h}$ before their infection with the virus. The virus (MOI 0.02) was subsequently added and allowed to infect for $2 \mathrm{~h}$, and then the inoculum was removed. The cells were washed with PBS, and then herbal drug extracts or compounds were added containing medium until $48 \mathrm{~h}$ post-infection (pi). The infected cell supernatant was quantified by quantitative real-time RTPCR and focus assay. To confirm our quantitative assay, the previously reported antiviral effects of remdesivir are used as positive control (Fig. 1). The resulting herbal drug $\mathrm{IC}_{50}$ values were 9.5, 1.2, and $5.4 \mu \mathrm{g} / \mathrm{ml}$ for Polygala Root ext., Areca ext. and Quercus Bark ext., respectively (Fig. 1). The $\mathrm{CC}_{50}$ values of Polygala Root ext., Areca ext., and Quercus Bark ext. were 186.3, 89.6, and $381.1 \mu \mathrm{g} / \mathrm{ml}$, respectively. Consequently, the selectivity indexes $\left(\mathrm{SI}=\mathrm{CC}_{50} / \mathrm{IC}_{50}\right)$ of Polygala Root ext., Areca ext., and Quercus Bark ext. were 19.7, 73.6, and 71.0, respectively. Additionally, the $\mathrm{IC}_{50}$ values of the natural chemical compounds baicalin and glabridin were $8.8 \mu \mathrm{M}$ and $2.5 \mu \mathrm{M}$, respectively (Fig. 1). The $\mathrm{CC}_{50}$ value for baicalin was $>1000 \mu \mathrm{M}$ and $21.5 \mu \mathrm{M}$ for glabridin. Consequently, the SI values of baicalin and glabridin were $>114.2$ and 8.7 , respectively.

We confirmed virus inhibition for Polygala Root ext., Areca ext., Quercus Bark ext. baicalin, and glabridin by measuring viral titer with a focus assay. Compared to virus control, Polygala Root ext., Areca ext., and Quercus Bark ext. showed significantly reduced virus titer with dosedependent manner ( $p$ values 0.009-0.02) (Fig. 2A). Subsequently, baicalin and glabridin significantly suppressed ( $p$ values 0.009-0.02) SARS-CoV-2 in a dose-dependent manner (Fig. 2B). We investigated the antiviral effect of Polygala Root ext., Areca ext., Quercus Bark ext., baicalin, and glabridin by immunofluorescence assay (IFA) to corroborate these results. The different concentrations of herbal drug extracts $(50 \mu \mathrm{g} / \mathrm{ml}$ and $25 \mathrm{ug} / \mathrm{ml})$, baicalin $(50 \mu \mathrm{M}$ and $25 \mu \mathrm{M})$, and glabridin $(12.5 \mu \mathrm{M}$ and $6.25 \mu \mathrm{M})$ showed the different NP expression levels (Fig. 3A and B).

A time-of-addition assay was performed to evaluate the herbal drug extracts, baicalin, and glabridin at the full-time entry, entry and post-entry treatments of the 

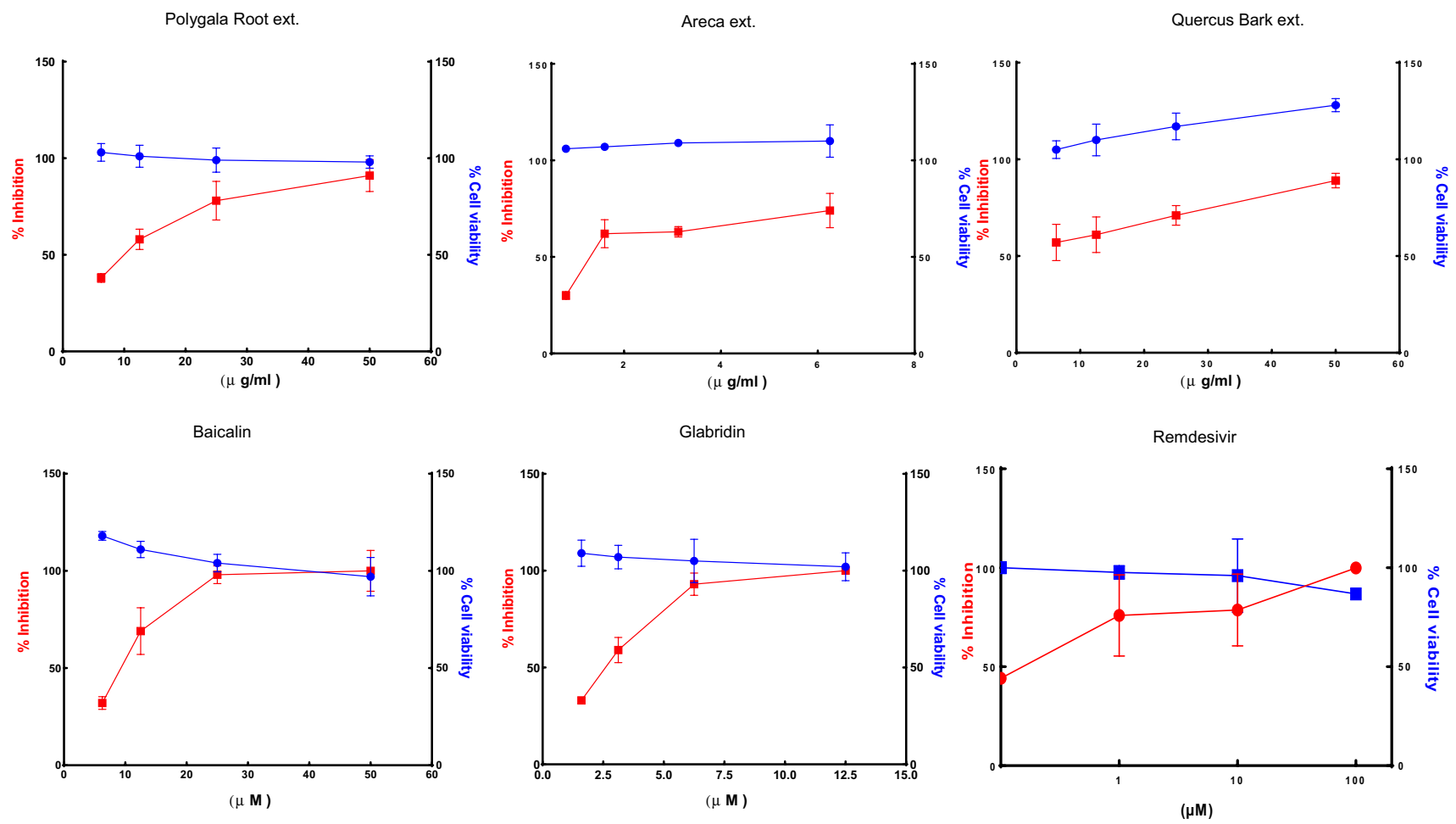

Fig. 1 Antiviral activity and cytotoxicity of the Polygala Root ext., Areca ext., Quercus Bark ext., baicalin, glabridin, and remdesivir against SARS-CoV-2in Vero E6 cells at 2 days pi, MOI 0.02. The red

square represents inhibition of SARS-CoV-2 infection (\%), and the blue circle represents cell viability $(\%)$. Values are mean $\pm \operatorname{SD}(N=3)$

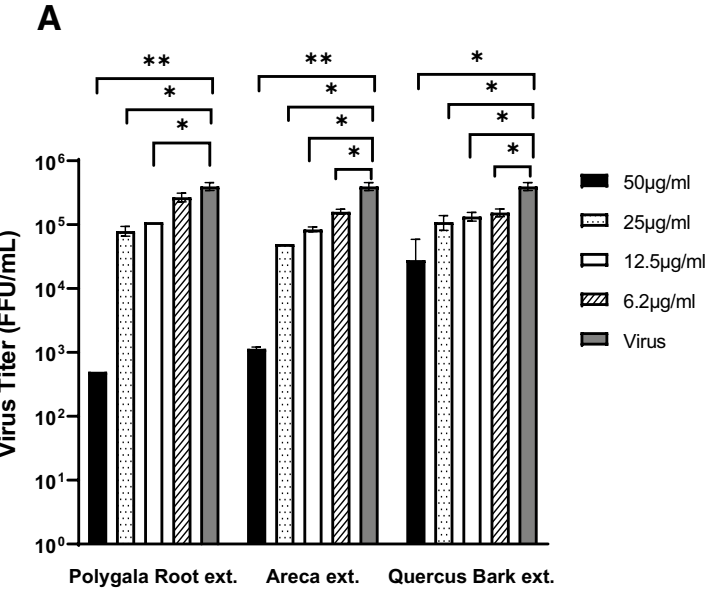

Fig. 2 Virus titer (FFU/mL) of Polygala Root ext., Areca ext., and Quercus Bark ext. (A), baicalin, and glabridin (B) significantly decreased SARS-CoV-2 infection at 2 days pi, MOI 0.02. Values are

SARS-CoV-2 life cycle. The Vero E6 cells were seeded in 96-well plates. For full-time treatment, cells were pretreated with the herbal drug extracts or compounds for $1 \mathrm{~h}$ before infection and then exposed to the virus for $2 \mathrm{~h}$ (MOI 0.1 ). The mixtures of virus and herbal drug extracts or compounds were then removed, and the cells were washed
B

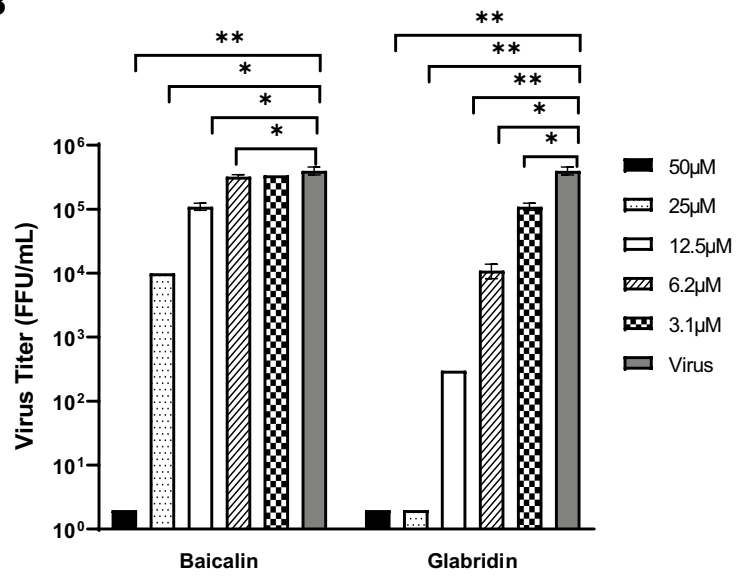

mean \pm SD $(N=3) .{ }^{*} p<0.05, * * p<0.01, * * p<0.001$ by Student's $t$ test between herbal drug extracts and compounds against virus control

with PBS. Next, cells were incubated with herbal drug extracts or compounds containing fresh medium for $16 \mathrm{~h}$ pi. For entry treatment, the procedure was the same as the full-time treatment, except cells were incubated without herbal drug extracts or compounds containing fresh medium for $16 \mathrm{~h}$ pi. For post-entry treatment, cells were 


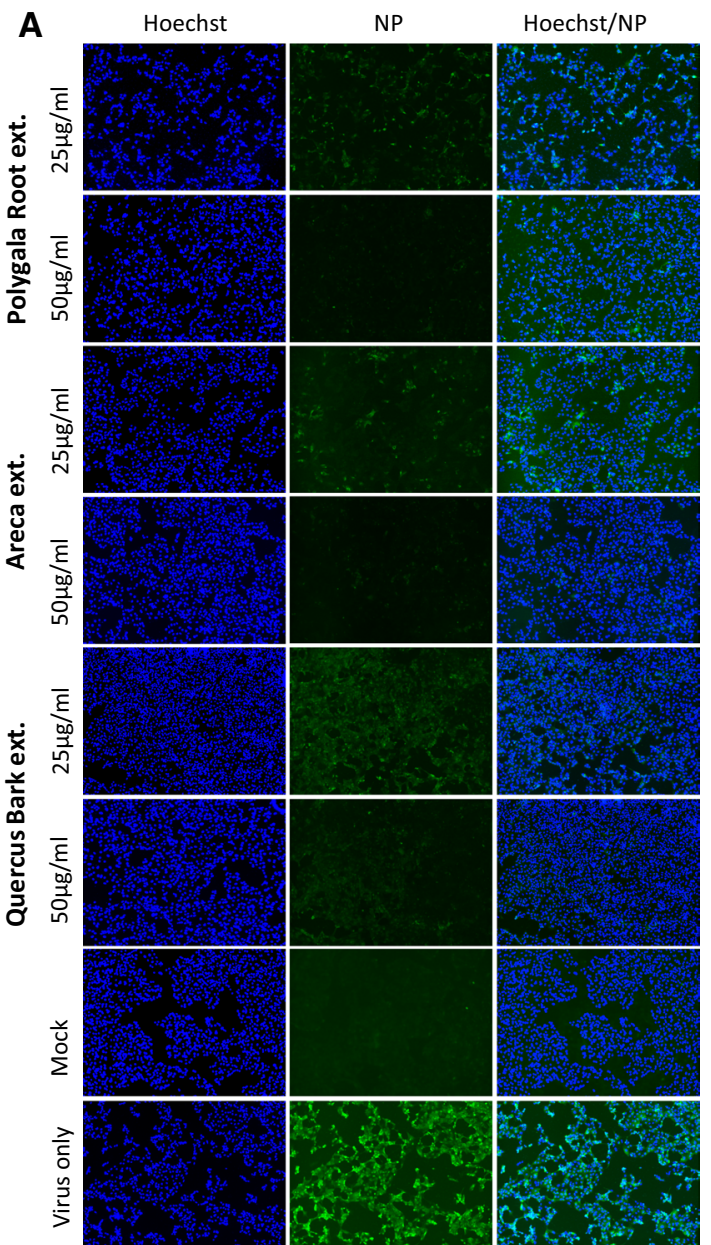

Fig. 3 Immunofluorescent assay of SARS-CoV-2 infection upon treatment using Polygala Root ext., Areca ext., and Quercus Bark ext. A, baicalin, and glabridin (B) at 2 days pi, MOI 0.02. The con-

exposed to the virus for $2 \mathrm{~h}$. After virus adsorption and cell washing, herbal drug extracts or compounds were added to the cells for $16 \mathrm{~h}$ pi. The dimethyl sulfoxide, DMSO (1\%) treated group was included as a mock control group in time-of-addition experiments. Cell lysates were collected for western blot analysis.

The NP expression in infected cells using western blot analysis demonstrated different intensity levels of viral protein in full-time entry, entry, and post-entry treatment of $50 \mu \mathrm{g} / \mathrm{ml}$ of Polygala Root ext., Areca ext., Quercus Bark ext., $50 \mu \mathrm{M}$ of baicalin, and $12.5 \mu \mathrm{M}$ of glabridin which all of them exhibited effective inhibition at full-entry treatment. The Polygala Root ext., Areca ext., and Quercus Bark ext. demonstrated virus inhibition in the full-time entry and entry treatments than post-entry treatments (Fig. 4A). The baicalin showed virus inhibition in the full-time entry and entry treatments, and glabridin showed virus inhibition in the full-time entry, entry, and post-entry treatments (Fig. 4B). Quantitative analysis by qRT-PCR for time-of-addition experiments

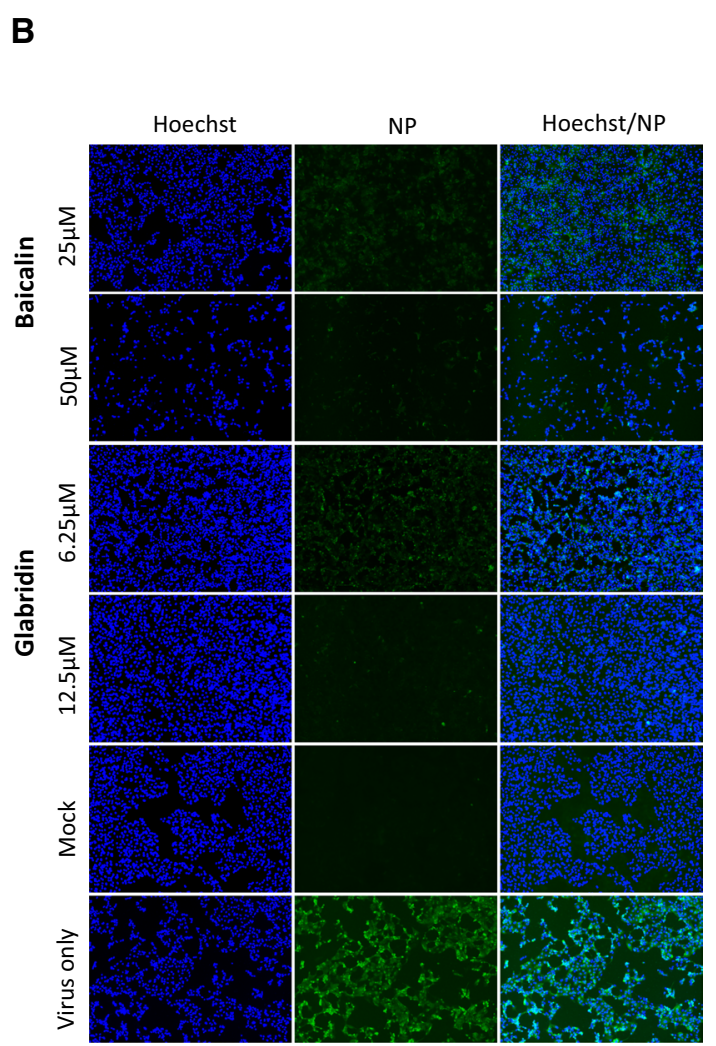

focal microscope images showed cell nuclei (blue) and SARS-CoV-2 nucleocapsid protein (green).

also showed virus inhibition in the full-entry, entry, and post-entry treatments for Polygala Root ext. (62\%, 51\%, and $26 \%)$, Areca ext. (71\%, 69\%, and 47\%), Quercus Bark ext. $(86 \%, 82 \%$, and $63 \%)$, baicalin $(67 \%, 63 \%$, and $30 \%)$, and glabridin (99\%, 85\%, and 46\%) (Fig. 5). The viral inhibition proportion was significantly different among full, entry, and post-entry stages of Polygala Root ext., Quercus Bark ext., baicalin and glabridin.

\section{Discussion}

COVID-19 continues to spread around the world and is hazardous to public health. New clinical features of multiple SARS-CoV-2 variants are being disseminated globally [20]. Despite the development of the COVID-19 vaccines, the search for new therapeutics is necessary. Many natural products, plants, and their secondary metabolites with activity against SARS-CoV-2 infection were recently reported 
Fig. 4 The SARS-CoV-2 viral protein expression on timeof-addition in full-time entry, entry, and post-entry treatments of $50 \mu \mathrm{g} / \mathrm{ml}$ of Polygala Root ext., Areca ext., and Quercus Bark ext. (A), $50 \mu \mathrm{M}$ of baicalin, $12.5 \mu \mathrm{M}$ of glabridin (B), and DMSO treatment by western blot analysis at $16 \mathrm{~h} \mathrm{pi}$, MOI 0.1

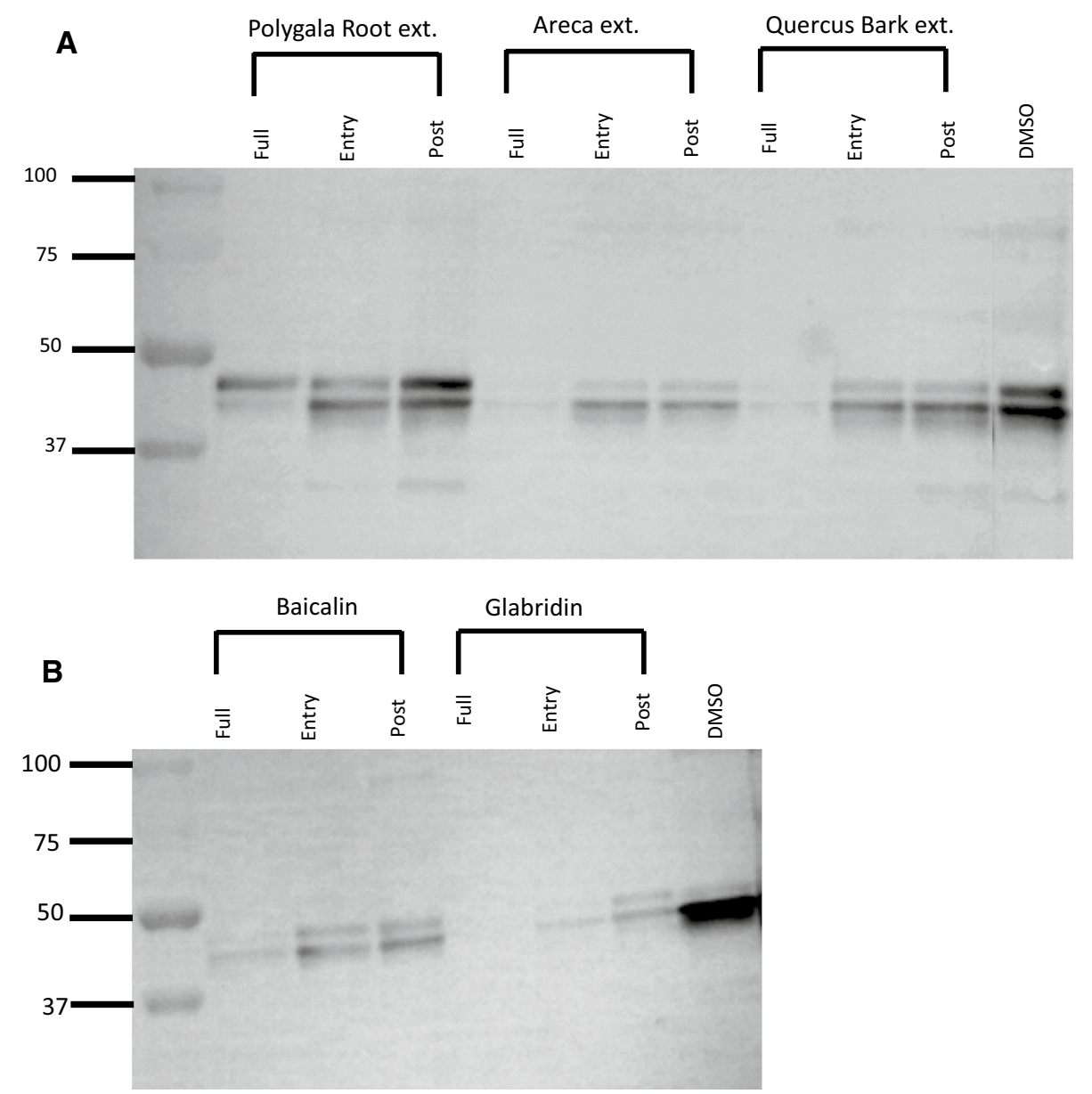

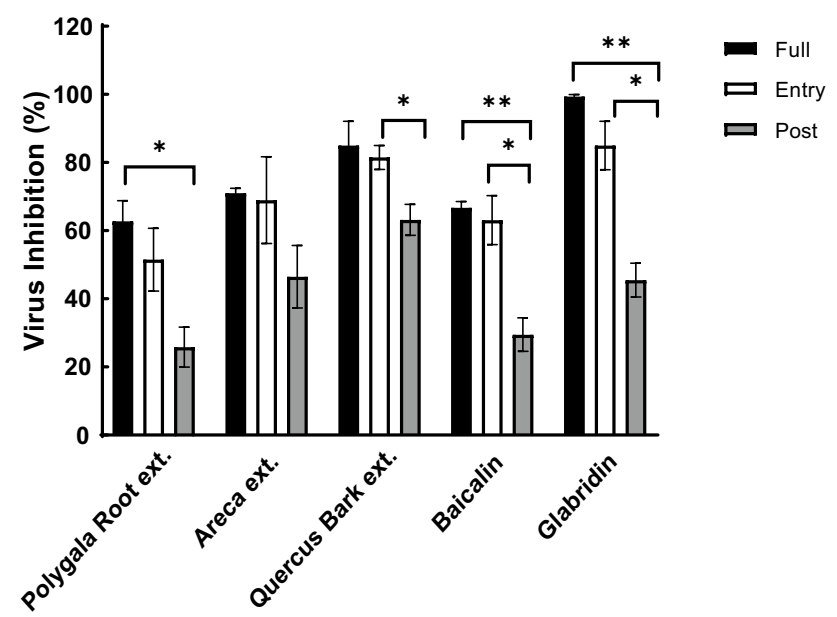

Fig. 5 Quantification of SARS-CoV-2 inhibition (\%) in the full-time entry, entry, and post-entry treatments of $50 \mu \mathrm{g} / \mathrm{ml}$ of Polygala Root ext., Areca ext., Quercus Bark ext., $50 \mu \mathrm{M}$ of baicalin, and $12.5 \mu \mathrm{M}$ of glabridin on qRT-PCR at $16 \mathrm{~h}$ pi, MOI 0.1 . The mean \pm SD were calculated from triplicate experiments. ${ }^{*} p<0.05$, $* * p<0.01$, $* * p<0.001$ between full-time entry, entry, and post-entry treatments after normalization with the virus control as SARS CoV-2 inhibitors [21, 22]. In the present study, we investigated the antiviral efficacy of herbal drug extracts of Polygala Root, Areca, Quercus Bark on SARS-CoV-2 infection in a dose-dependent manner. Polygala Root (root of Polygala tenuifolia Willdenow, Japanese name “onji”), a well-known herbal drug traditionally used as an expectorant and sedative, has attracted growing interest in recent years owing to its newly found pharmacological effect related to neuroprotection [23]. Areca (ripe seed of Areca catechu Linné, Japanese name "binroji") is a herbal drug used in Japanese Kampo formulas that have been reported to regulate the proliferation through autophagy of human hepatocellular carcinoma HepG2 cells [24], leukemic Jurkat T cells [25], and oral carcinoma cells [26]. The extract from Quercus Bark (bark of Quercus acutissima Carruthers, Q. serrata Murray, $Q$. mongolica Fischer ex Ledebour var. crispula Ohashi, or $Q$. variabilis Blume, Japanese name "bokusoku") has been used in folk medicine to treat skin disorders and acne vulgaris [27]. A $50 \mu \mathrm{g} / \mathrm{ml}$ concentration of these three herbal drug extracts without cytotoxicity inhibited SARSCoV-2 in 75-100\% of both viral RNA levels and infectious virus titers. As SARS-CoV-2 spike proteins bind to the receptor hACE2 [7], the herbal drug extracts showed 
virucidal activity with IFA by different expression levels of virus NP protein at a dose-dependent manner. In viral protein analysis, the antiviral activity in three herbal drug extracts was different between entry and post-entry conditions. Moreover, the SI values of Areca ext. and Quercus Bark ext. (73.6 and 71.0, respectively) showed a considerable safety profile for further development as an antiviral therapeutic agent.

Our study also showed $100 \%$ inhibition of SARS-CoV-2 by baicalin at a concentration of $25 \mu \mathrm{M}$. Baicalin is a flavonoid extracted from Scutellaria Root (root of Scutellaria baicalensis Georgi), an important traditional Chinese medicine that exhibits various anti-inflammatory and antiviral effects and has been reported to be useful in treating cancer, hypertension, and cardiovascular diseases [28, 29]. Another study has also reported that baicalin inhibited SARS-CoV-2 $3 \mathrm{CL}$ protease in vitro [30-32]. The baicalein, the aglycone of baicalin inhibited SARS-CoV-2/ vesicular stomatitis virus by interfering mitochondrial oxidative phosphorylation in mPTP dependent manner [33]. In addition, baicalein inhibited SARS-CoV-2 induced injury in vitro and in vivo [34]. As baicalin and baicalein showed SAR-CoV-2 RNAdependent RNA polymerase inhibitors [35]. Here, our study indicated via viral protein analysis that baicalin inhibits SARS-CoV-2 in the full-time entry and entry treatments.

Glabridin, another flavonoid, is a component of licorice (Glycyrrhiza glabra) root, native to Europe and Asia [36]. Glabridin has multiple pharmacological activities such as antiviral, anti-inflammatory, anti-tumor, and antimicrobial effects [37]. Further, licorice root including flavonoids glycyrrhizin, liquiritigenin and glabridin showed antiviral property on SARs-CoVs. We demonstrated that glabridin effectively inhibited $100 \%$ of SARS-CoV-2 replication at a concentration of $6.25 \mu \mathrm{M}[36,38]$. The data from the viral RNA levels were consistent with results from the infectious virus titers. Interestingly, glabridin suppressed SARS-CoV-2 infection at the full-time entry and post-entry treatments in viral protein levels. This behavior is reflected in a similar current result for the antiviral efficacy of glycyrrhizin, the primary active ingredient of licorice root [39, 40]. However, glabridin also effectively inhibited SARS-CoV-2 at the entry treatment in our study. Other investigators confirmed that glycyrrhizin and licorice extracts overcome SARS-CoV-2 infection [41, 42]. The molecular docking study indicated licorice active compounds such as glycyrrhizic acid, liquiritigenin and glabridin against main protease of SARS-CoV-2.

Herbal drugs are promising therapeutic agents against SARS-CoV-2 and should be subject to further investigation in vivo and subsequent clinical trials. Our findings and those of previous reports indicate that baicalin is a natural-product inhibitor against SARS-CoV-2. Our study also highlights glabridin as a potential antiviral compound. Additional studies in vivo and clinical trials are still required to determine how these compounds might be used for the treatment of COVID-19.

Supplementary Information The online version contains supplementary material available at https://doi.org/10.1007/s11418-021-01596-w.

Acknowledgements We thank all the members of Department of Virology, Institute of Tropical Medicine, Nagasaki University, Japan. This research was performed using the INM deposited WAKANYAKU library, Institute of Natural Medicine, University of Toyama, Japan. This research was supported by Japan Program for Infectious Diseases Research and Infrastructure, Japan Agency for Medical Research and Development (AMED) under Grant Number JP21wm0125006.

\section{Declarations}

Conflict of interest The authors declare no conflict of interest.

\section{References}

1. Yang X, Yu Y, Xu J et al (2020) Clinical course and outcomes of critically ill patients with SARS-CoV-2 pneumonia in Wuhan, China: a single-centered, retrospective, observational study. Lancet Respir Med 8:475-481. https://doi.org/10.1016/S22132600(20)30079-5

2. Kumar D, Chauhan G, Kalra S et al (2020) A perspective on potential target proteins of COVID-19: Comparison with SARS-CoV for designing new small molecules. Bioorg Chem 104:104326. https://doi.org/10.1016/j.bioorg.2020.104326

3. Wang C, Horby PW, Hayden FG, Gao GF (2020) A novel coronavirus outbreak of global health concern. Lancet 395:470-473. https://doi.org/10.1016/S0140-6736(20)30185-9

4. World Health Organization Coronavirus Disease (COVID-2019) situation reports (World Health Organization, 2020)

5. World Health Organization. https://covid19.who.int/ updated by 11/December/2021.6.

6. He F, Deng Y, Li W (2020) Coronavirus disease 2019: what we know? J Med Virol 92:719-725. https://doi.org/10.1002/jmv. 25766

7. Shang J, Wan Y, Luo C et al (2020) Cell entry mechanisms of SARS-CoV-2. Proc Natl Acad Sci 117:11727-11734. https://doi. org/10.1073/pnas.2003138117

8. Zhu N, Zhang D, Wang W et al (2020) A novel coronavirus from patients with pneumonia in China, 2019. N Engl J Med 382:727733. https://doi.org/10.1056/NEJMoa2001017

9. V'kovski P, Kratzel A, Steiner S et al (2021) Coronavirus biology and replication: implications for SARS-CoV-2. Nat Rev Microbiol 19:155-170. https://doi.org/10.1038/s41579-020-00468-6

10. Yim SK, Kim K, Kim IH et al (2021) Inhibition of SARS-CoV-2 virus entry by the crude polysaccharides of seaweeds and abalone viscera in vitro. Mar Drugs. https://doi.org/10.3390/md19040219

11. Ashburn TT, Thor KB (2004) Drug repositioning: identifying and developing new uses for existing drugs. Nat Rev Drug Discov 3:673-683. https://doi.org/10.1038/nrd1468

12. Wang Y, Zhang D, Du G et al (2020) Remdesivir in adults with severe COVID-19: a randomised, double-blind, placebo-controlled, multicentre trial. Lancet 395:1569-1578. https://doi.org/ 10.1016/s0140-6736(20)31022-9

13. Hassanipour S, Arab-Zozani M, Amani B et al (2021) The efficacy and safety of Favipiravir in treatment of COVID-19: a systematic review and meta-analysis of clinical trials. Sci Rep 11:11022. https://doi.org/10.1038/s41598-021-90551-6 
14. Jan JT, Cheng TR, Juang YP et al (2021) Identification of existing pharmaceuticals and herbal medicines as inhibitors of SARSCoV-2 infection. Proc Natl Acad Sci USA. https://doi.org/10. 1073/pnas.2021579118

15. Kiba Y, Oyama R, Misawa $S$ et al (2021) Screening for inhibitory effects of crude drugs on furin-like enzymatic activities. J Nat Med. https://doi.org/10.1007/s11418-021-01519-9

16. Teklemichael A, Mizukami S, Toume K et al (2020) Anti-malarial activity of traditional Kampo medicine Coptis rhizome extract and its major active compounds. Malar J 19:204. https://doi.org/10. 1186/s12936-020-03273-x

17. Ngwe Tun MM, Muthugala R, Nabeshima T et al (2020) Complete genome analysis and characterization of neurotropic dengue virus 2 cosmopolitan genotype isolated from the cerebrospinal fluid of encephalitis patients. PLoS ONE 15:e0234508. https://doi.org/10. 1371/journal.pone. 0234508

18. Shirato K, Nao N, Katano H et al (2020) Development of genetic diagnostic methods for detection for Novel Coronavirus 2019(nCoV-2019) in Japan. Jpn J Infect Dis 73:304-307. https:// doi.org/10.7883/yoken.JJID.2020.061

19. Ngwe Tun MM, Thant KZ, Inoue S et al (2013) Serological characterization of dengue virus infections observed among dengue hemorrhagic fever/dengue shock syndrome cases in upper Myanmar. J Med Virol 85:1258-1266. https://doi.org/10.1002/jmv. 23577

20. Alhadrami HA, Sayed AM, Hassan HM et al (2021) Cnicin as an anti-SARS-CoV-2: an integrated in silico and in vitro approach for the rapid identification of potential COVID-19 therapeutics. Antibiotics 10:542

21. Sayed AM, Khattab AR, AboulMagd AM et al (2020) Nature as a treasure trove of potential anti-SARS-CoV drug leads: a structural/mechanistic rationale. RSC Adv 10:19790-19802. https:// doi.org/10.1039/D0RA04199H

22. Owis AI, El-Hawary MS, El Amir D et al (2020) Molecular docking reveals the potential of Salvadora persica flavonoids to inhibit COVID-19 virus main protease. RSC Adv 10:19570-19575. https://doi.org/10.1039/D0RA03582C

23. Uchikura T, Sugiwaki H, Yoshimura M et al (2018) Characterization of UV-sensitive marker constituents of polygala root for TLC: applications in quality control of single crude drug extract preparations. Chem Pharm Bull 66:1174-1180. https://doi.org/10. 1248/cpb.c18-00616

24. Okubo S, Komori H, Kuwahara A et al (2019) Screening of crude drugs used in japanese kampo formulas for autophagy-mediated cell survival of the human hepatocellular carcinoma cell line. Med. https://doi.org/10.3390/medicines6020063

25. Yen CY, Chiang WF, Liu SY et al (2015) Impacts of autophagyinducing ingredient of areca nut on tumor cells. PLoS ONE 10:e0128011. https://doi.org/10.1371/journal.pone.0128011

26. Wu D-H, Jia C-C, Chen J et al (2014) Autophagic LC3B overexpression correlates with malignant progression and predicts a poor prognosis in hepatocellular carcinoma. Tumor Biol 35:1222512233. https://doi.org/10.1007/s13277-014-2531-7

27. Koseki J, Matsumoto T, Matsubara Y et al (2015) Inhibition of rat $5 \alpha$-reductase activity and testosterone-induced sebum synthesis in hamster sebocytes by an extract of quercus acutissima cortex. Evid Based Complement Altern Med 2015:853846. https://doi. org/10.1155/2015/853846
28. Tao Y, Zhan S, Wang Y et al (2018) Baicalin, the major component of traditional Chinese medicine Scutellaria baicalensis induces colon cancer cell apoptosis through inhibition of oncomiRNAs. Sci Rep 8:14477. https://doi.org/10.1038/s41598-018-32734-2

29. Moghaddam E, Teoh B-T, Sam S-S et al (2014) Baicalin, a metabolite of baicalein with antiviral activity against dengue virus. Sci Rep 4:5452. https://doi.org/10.1038/srep05452

30. Su H, Yao S, Zhao W et al (2020) Discovery of baicalin and baicalein as novel, natural product inhibitors of SARS-CoV-2 3CL protease in vitro. bioRxiv. https://doi.org/10.1101/2020.04.13. 038687

31. Liu H, Ye F, Sun Q et al (2021) Scutellaria baicalensis extract and baicalein inhibit replication of SARS-CoV-2 and its 3C-like protease in vitro. J Enzym Inhib Med Chem 36:497-503. https:// doi.org/10.1080/14756366.2021.1873977

32. Su H, Yao S, Zhao W et al (2020) Anti-SARS-CoV-2 activities in vitro of Shuanghuanglian preparations and bioactive ingredients. Acta Pharmacol Sin 41:1167-1177. https://doi.org/10.1038/ s41401-020-0483-6

33. Huang S, Liu Y, Zhang Y et al (2020) Baicalein inhibits SARS$\mathrm{CoV}-2 / \mathrm{VSV}$ replication with interfering mitochondrial oxidative phosphorylation in a mPTP dependent manner. Signal Transduct Target Ther 5:266. https://doi.org/10.1038/s41392-020-00353-x

34. Song J, Zhang L, Xu Y et al (2021) The comprehensive study on the therapeutic effects of baicalein for the treatment of COVID-19 in vivo and in vitro. Biochem Pharmacol 183:114302. https://doi. org/10.1016/j.bcp.2020.114302

35. Zandi K, Musall K, Oo A et al (2021) Baicalein and baicalin inhibit SARS-CoV-2 RNA-dependent-RNA polymerase. Microorganisms. https://doi.org/10.3390/microorganisms 9050893

36. Pilcher H (2003) Liquorice may tackle SARS. Nature. https://doi. org/10.1038/news030609-16

37. Wang L, Yang R, Yuan B et al (2015) The antiviral and antimicrobial activities of licorice, a widely-used Chinese herb. Acta Pharm Sin B 5:310-315. https://doi.org/10.1016/j.apsb.2015.05.005

38. Patel SKS, Lee J-K, Kalia VC (2020) Deploying biomolecules as anti-COVID-19 agents. Indian J Microbiol 60:263-268. https:// doi.org/10.1007/s12088-020-00893-4

39. van de Sand L, Bormann M, Alt M et al (2021) Glycyrrhizin effectively inhibits SARS-CoV-2 replication by inhibiting the viral main protease. Viruses. https://doi.org/10.3390/v13040609

40. Diomede L, Beeg M, Gamba A et al (2021) Can antiviral activity of licorice help fight COVID-19 infection? Biomolecules 11:855

41. Gomaa AA, Abdel-Wadood YA (2021) The potential of glycyrrhizin and licorice extract in combating COVID-19 and associated conditions. Phytomed Plus 1:100043. https://doi.org/10.1016/j. phyplu.2021.100043

42. Ng SL, Khaw K-Y, Ong YS et al (2021) Licorice: a potential herb in overcoming SARS-CoV-2 infections. J Evid-Based Integr Med 26:2515690X21996662. https://doi.org/10.1177/2515690x21 996662

Publisher's Note Springer Nature remains neutral with regard to jurisdictional claims in published maps and institutional affiliations. 